Please do not remove this page

RMIT

UNIVERSITY

\title{
The courtyard in rural homesteads of Bangladesh
}

Ahmed, Iftekhar

https://researchrepository.rmit.edu.au/esploro/outputs/9921861842001341/filesAndLinks?institution=61RMIT_INST\&index=null

Ahmed, I. (2012). The courtyard in rural homesteads of Bangladesh. Vernacular Architecture, 43, 47-57. https://doi.org/10.1179/0305547712Z.0000000005

Document Version: Accepted Manuscript

Published Version: https://doi.org/10.1179/0305547712Z.0000000005

Repository homepage: https://researchrepository.rmit.edu.au

(c) The Vernacular Architecture Group 2012.

Downloaded On 2023/04/26 09:20:41 +1000

Please do not remove this page 
Thank you for downloading this document from the RMIT Research Repository.

The RMIT Research Repository is an open access database showcasing the research outputs of RMIT University researchers.

RMIT Research Repository: http://researchbank.rmit.edu.au/

\section{Citation:}

Ahmed, I 2012, 'The courtyard in rural homesteads of Bangladesh', Vernacular Architecture, vol. 43, pp. 47-57.

See this record in the RMIT Research Repository at:

http://researchbank.rmit.edu.au/view/rmit:20451

Version: Accepted Manuscript

Copyright Statement: (c) The Vernacular Architecture Group 2012.

Link to Published Version:

http://dx.doi.org/10.1179/0305547712Z.0000000005 


\title{
The Courtyard in Rural Homesteads of Bangladesh
}

\author{
Iftekhar Ahmed, PhD \\ Research Fellow, School of Architecture \& Design, RMIT University, \\ Melbourne, VIC 3000, Australia
}

\section{ABSTRACT}

In rural settlements of the floodplains in Bangladesh, an intrinsic element is the homestead. The homestead layout is defined by the courtyard, formed by the arrangement of dwelling units and ancillary buildings around a rectangular open space. The courtyard has important physical and functional characteristics derived from local climatic requirements and living patterns. However, particularly in this predominantly Muslim society, the cultural norm of maintaining women's privacy is an important factor behind the development of this archetypal space. Nonetheless other ethnic communities in the floodplains also often have courtyards, suggesting that it is a regional archetype. The archetypal courtyard is being subject to transformation due to social, economic and environmental changes. If this trend continues, it would signal the loss of an important and long-lasting regional expression that has resulted from the blending of culture, climate and nature, posing questions on its future reinterpretation.

Key words: Homestead, courtyard typologies, climatic aspects, cultural aspects, changing patterns. 


\section{RURAL SETTLEMENT PATTERNS}

In predominantly rural (more than 70 per cent) Bangladesh, the major part of the land consists of low-lying alluvial floodplains, which is part of a large river basin or delta with annual flooding of the numerous rivers and water bodies that characterise the landscape. There are broadly two main types of rural settlement: elongated-linear and amorphous (Sultana, 1993), both consisting of settlements built on raised or high land above the annual flood level. The elongated linear type is built on natural levees of rivers or water channels (see Fig. 1). The amorphous type, consisting of clustered or scattered settlements, is usually dispersed throughout the terrain. Throughout the floodplains, entire villages and towns have grown over time in the amorphous pattern by raising land and establishing settlements on it, and such settlements still continue to be built. These settlements are elevated to adapt to the annual flooding, but during extreme flooding events they often cannot avoid inundation.

Where high land is not available, earth obtained from excavating ponds or channels is raised into a mound about 2 to 3 metres high depending on the surrounding water level, on which a homestead or bari is established. A bari often begins with an individual household and incrementally develops into a settlement of several ghors (dwelling units and ancillary structures) of intergenerational households belonging to a joint or extended family. Over time more earth is added to extend the mound at the sides and the settlement gradually expands thereby in an amorphous pattern. In many places settlements established this way on raised mounds are scattered throughout 
the low-lying terrain and in the rainy season virtually become islands (see Fig. 2).

\section{HOMESTEAD AND COURTYARD}

A typical morphological feature of the rural homestead or bari is the arrangement of a number of closely spaced single-storey (or sometimes double-storey) one to two roomed rectangular buildings (ghors) around a square or rectangular open courtyard (uthan) (see Figs. 3 and 4). There is usually a single row of buildings around the courtyard. At the initial stage of the homesteading process, typically, a pond is excavated to obtain soil for raising the land; a backyard pond with bathing steps (pukur ghat) can be found in many large homesteads. The pond allows rearing ducks and fish, and bathing - a regular cleansing ritual in this tropical land.

After raising land, each homestead begins on the mound with a main dwelling unit (boshoth ghor). Ancillary structures such as kitchens (ranna ghor), granaries (gola ghor) and cowsheds (goyal ghor) are built gradually over time around a central open space, and thus begin to define the courtyard. The word ghor literally means 'room', indicating that the individual units are perceived actually as rooms with specific functions and not really as buildings; the bari consisting of several ghors around a courtyard is considered the unit of home. The main ghor is usually a well-built structure on the homestead and the ancillary structures tend to be semi-permanent and built of perishable materials. As the family grows, these are moved to peripheral locations and more dwelling 
units are added around the courtyard. The courtyard serves as the main circulation space between the buildings arranged around it.

Dwelling units flanking the courtyard often have shaded open verandas facing the courtyard, which provide cool outdoor spaces. In some cases verandas are partially or fully enclosed by screen-type walls for privacy and additional shade. The veranda is a semi-private space and serves as a transition zone from the semi-public courtyard to the private house interior. Generally, the buildings comprising the homestead range in size from 2 metres by 3.5 metres to 4 metres by 7 metres, and face all sides of the courtyard, but entered only through the courtyard. The buildings have one to two rooms and are usually single-storey, although in some well-to-do homesteads some two-storied buildings can also be found. Buildings are usually constructed on a raised plinth of compacted earth and the floor is left bare. This additional flood-proofing technique is ubiquitous throughout Bangladesh and is a characteristic feature of rural housing. The plinth varies from a height of about 15 centimetres in higher areas to 120 centimetres in low-lying areas. Walls are commonly porous screens made of organic materials such as bamboo, reeds or grasses; in drier and hilly regions the walls are also made of earth. Pitched roofs are typical, thatched with different types of grasses or straw according to local availability, but corrugated iron $(\mathrm{Cl})$ sheet has now become widely popular and common in rural areas, mainly for roofs and increasing for also walls. These features of rural settlement and housing have been described in more detail elsewhere by the author (Ahmed, 1997; Ahmed, 2003). 


\section{TYPES OF COURTYARD}

Although there is considerable variety, four main types of courtyard arrangement can be highlighted, as documented by Hasan (1987) and Islam et al (1981). At the initial stage of establishing a homestead, a single dwelling unit, usually with an outdoor kitchen, is built facing a front yard. This, however, does not really represent a courtyard typology per se; rather it is the preliminary stage of homestead formation, which incrementally develops into more elaborate arrangements. Thus the second type, or subsequent stage, consists of several buildings usually belonging to a single household ${ }^{1}$, around an 'independent' courtyard, comprising a main dwelling unit with ancillary structures and subsidiary dwelling units for the next generation of family members when they grow up - often an incremental development of the first type. The third type or stage results from further development as new households are formed gradually, an outcome of family growth. More houses are built along the courtyard, resulting in a 'common' courtyard, often requiring extension of the courtyard and relocation of ancillary structures. The most elaborate arrangement, the fourth type and final stage, is that of 'interlocking' courtyards with open passageways linking different households. This represents a horizontal extension of the family over space: as the family grows, the homestead is extended into adjacent land and new courtyards with buildings around them are built. The gaps between buildings serve to define passageways 'interlocking' the courtyards. The latter two arrangements arise

\footnotetext{
${ }^{1}$ Household is defined here as a group sharing a common kitchen and eating arrangements.
} 
from expansion of the homestead and the extended family; kin usually relates most households with shared or linked courtyards.

In Hindu, or non-Muslim ethnic communities, where seclusion of women is less pronounced, a more open arrangement of interlocking courtyards can sometimes be found (Hasan, 1987). In some cases here, instead of passageways linking the courtyards, the corners of the courtyards merge with each other forming almost a large contiguous multi-sided courtyard (see Fig. 5). Chowdhury (1992) has documented some other types of courtyards including adjacent, walled and multiple courtyards. The adjacent courtyard is similar to the common courtyard described above, but different because here two or more sets of unrelated extended families build houses along the periphery of adjoining courtyards. Walled and multiple courtyards belong to large and relatively wealthy families and are not prevalent extensively.

\section{PHYSICAL AND FUNCTIONAL ASPECTS}

Extension of a homestead is not carried out by extending the dwelling units, except for small additions; rather, new structures are built around the courtyard as need arises. Thus a rural homestead usually consists of several one or two roomed buildings constructed incrementally. The homestead represents the habitat of the extended family and each separate dwelling unit within it represents the habitat of individual households or family members. Historical accounts of housing in this region indicate the continuity of this pattern from earlier times (King, 1984), but reasons for it are generally not analysed. 
Possibly, and perhaps primarily, the humid climate necessitates separate buildings to maximise cross-ventilation, more difficult to achieve in larger buildings with many rooms. Although the buildings are unattached, they are placed closely with small gaps between them ranging generally from 70 centimetres to 1.25 metres and their long sides flank the courtyard so that the courtyard as a rectangular introverted space becomes evident and defined. In this way a set of buildings laid out separately around a courtyard behaves as a unit. Even though separate, they work as a group because of the interrelationships of their functions and the inherent concept that these separate buildings are actually rooms comprising a larger unit of the home; the word ‘bari' literally signifies 'home'.

The courtyard layout also relates to the cultural need for privacy, and along with the need to have separate buildings to relieve climatic discomfort, has resulted in this particular type of courtyard housing in rural Bangladesh. The courtyard allows defining an introverted layout of the homestead; the built units are accessible only from the courtyard and face away from the external realm. This introverted layout is further accentuated by planting trees extensively on the periphery of the homestead along the outer walls of the buildings. From the outside, a clump of trees indicates a homestead (see Fig. 6).

A north-south orientation of the main dwelling unit is preferred, with its long side along the courtyard facing south to benefit from the prevailing southern breeze. Dwelling units built subsequently have to compromise their orientation in order 
to face the central rectangular courtyard, thus ostensibly also compromising their climatic performance. However several studies suggest that extensive protective cover by vegetation and the use of a courtyard reduces overall heat gain considerably (Hasan, 1985; Olgay, 1963). The courtyard draws in air and ventilates the buildings facing it, once again an illustration of how the homestead here functions as a unit. The climatic performance of individual buildings is relegated to serve the overall collective performance of the homestead. Trees planted along the homestead boundary and in the gaps between buildings together with the built structures form almost a continuous edge for the courtyard, thus defining its singularity and allowing its function of drawing in air. Other than a small altar-planter for the holy tulsi tree in some Hindu homesteads, the courtyard is mostly kept unfettered of vegetation and structures. The surface is regularly plastered with mud slurry for smoothness and most courtyard activities are carried out upon the levelled mud-paved ground without need for built structures; squatting or sitting on low seats (pidi, mora) or mats enables functionality to the ground. The courtyard functions as a bounded open-to-sky private area, almost akin to indoor space.

In this warm climate, the courtyard is virtually an extension of indoor living and allows a variety of activities: processing agricultural produce, making household artefacts, drying clothes and food items, cooking, chatting, etc (see Fig. 7). Social events such as weddings are also held in the courtyard, especially in the larger ones. Even the gaps between the buildings are utilised for outdoor activities because they tend to be shaded. However, it is uncommon to sleep in 
the courtyard despite the hot-humid climate for fear of evil spirits or assault, because although visually private, the courtyard has a sense of openness and is accessible from the outside. During the day, the courtyard becomes the territory of women because most of the men are away working in the fields or outside the homestead. In addition to various household activities, women also visit neighbours and spend time in their courtyards, undisturbed because of the general absence of men during the daytime. Adult male family members of the homestead mostly tend to spend the time within the precinct of the homestead during meals and at night for sleep, and sometimes during the evening. For men, especially the younger, the major part of the day is spent away from the homestead. Even if they are back in the evening, they gather outside in the surroundings of the homestead to meet friends and neighbours.

\section{CULTURAL ASPECTS}

In traditional rural Muslim homesteads of this predominantly Islamic country, the courtyard is the private inner domain of women; hence various measures are followed to maintain their purdah (privacy; seclusion for modesty). Chowdhury (1992) has documented the various types of entry into the typically introverted homestead; in most cases entrance into the courtyard and thereby the homestead is always indirect or arranged in such a way that view into the courtyard from the outside is obstructed. An indirect entry is obviously less intrusive, assists in maintaining privacy and allows preparation or warning before admittance of men or outsiders. Vegetation and screens are used additionally to ensure privacy and also to provide shade, adding to the private 
ambience. The layout of the homestead with the long sides of the buildings flanking the courtyard creates small gaps or passages between the buildings linking the courtyard to the outside. Some of these passages are used as entries into the homestead and act as a filtering mechanism to allow entry of only familiar or approved men; gaps not used for circulation are veiled off with vegetation and screens to block outside view.

There is a gendered division and related use of space in rural homesteads according to Islamic ideals of purdah. The outer area near the main entry of the homestead compound belongs to the men and often a structure for male gatherings (baithak ghor) is built there. As documented by Hasan (1987), often in large homesteads an outer court used mainly by men is built. It is uncommon for unrelated men to enter a courtyard directly; they are usually received in the front area of the homestead. If there is at all need for them to enter the homestead, established by reception outside, they are then invited inside to sit in the courtyard or a veranda where the older men or relevant household heads give them company, while the women tend to retreat into the dwellings or kitchens.

In addition to the physical separation of male and female domains, the privacy of women is further achieved through behavioural adjustments. For example, when male members of distant kin or unrelated community members enter the courtyard, it is preceded by warnings such as clearing the throat, singing, calling, etc to alert the women within the homestead to adjust behaviour and 
adopt modesty, such as covering the head and withdrawing inside the buildings. It is necessary to first enter the courtyard in order to enter the individual dwellings. In addition to security, for household male members this sequential entry into the homestead allows preparation for adjusting to a private and domestic domain.

Even in the case of male family members residing within the homestead, there are specific codes of behaviour relating to the concept of female modesty. For instance, men generally do not enter the kitchen, at least not without warning. There are specific allocated periods for female use of household or communal toilets, usually when it is dark at dawn or evening; men avoid these timings. Similarly women bathe in the pond during the day when men are away at work, whilst men bathe in the morning before going to work, or in the evening after returning. The time-specific use of space according to the period of the day or time zoning, that is, separate use of the same space within the homestead by men and women during different times of the day, is a common strategy of gender-orientated wilful avoidance. A strong basis of time zoning is the local lifestyle where men tend to spend most of the day away from the homestead. Women spend the bulk of their time within the homestead and the bounded courtyard provides them a private inner sanctum during daytime.

Although in Hindu and tribal communities the gender-specific use of space is less rigorous, Hasan (1985) has noted that the courtyard pattern is also evident widely in such communities throughout the floodplains. Notwithstanding small 
differences, the pattern is not entirely dissimilar to that of the Muslims. This widespread prevalence of the courtyard indicates that it is a regional typology that has developed to serve the need for a multi-purpose space that accommodates local patterns of outdoor activity. In Hindu homesteads, symbols of religious ritual, such as the holy tulsi tree in a planter or an altar with ceremonial statues of deities, are placed in the courtyard. Here the courtyard is maintained well by daily sweeping, usually in the morning, and plastered frequently every few days with a mixture of mud and cow dung; as cows are considered holy by Hindus, the use of cow dung is believed to be auspicious. This Hindu traditional practice of courtyard maintenance is perceived to bestow well-being on the family, failing which is believed to usher bad fortune. A similar practice is followed also in Muslim communities, but without the conscious spiritual connotation and bovine connection. Because of this perhaps, as many local observers comment, courtyards in Muslim homesteads do not appear as well maintained as in Hindu homesteads.

It should be noted however that the courtyard typology is prevalent largely in the rural floodplains of Bangladesh, with some cultural nuances, but in the tribal communities of the hilly areas, such as the Chittagong Hill Tracts, the courtyard is largely absent. Here settlement patterns are usually linear, with roads or walkways defining circulation and community space (Ahmed and Kabir, 2005). Seclusion or modesty of women is of lesser concern here compared to the predominantly Muslim society of the plains. This alternative typology is possibly 
a result of the hilly topography and the cultures of the people inhabiting these areas, which are different both from the terrain and lifestyles of the plains.

The significance of the courtyard as a regional typology, suggesting that is a cultural archetype, is reflected even in modern urban houses and apartments, where it is manifested in a compact consolidated form (Rahman, 1996). Urban houses are essentially a transformation of the rural homestead pattern, compacted to account for the higher cost and demand of urban land. Here rooms, called ghors even in this context, are grouped around a central dining/family space, similar to the rural courtyard, but in a compact fashion (see Fig. 8). Although unlike the rural extended family homestead, urban apartments are built typically for nuclear families, many aspects of behaviour relating to privacy described above are nonetheless followed: receiving guests at the front, indirect entry into the house, gender-based time-zoning, etc. Experiencing rapid but only recent urbanisation, Bangladesh still remains largely rural. Most people in cities have rural roots and thus many rural behavioural and cultural traits persist in the urban context; the similarity in layout and use of space between the rural homestead and urban apartments is an example of such continuity.

\section{CHANGING PATTERNS}

In some rural settlements, the archetypal courtyard is now built smaller or even excluded because of increasing population density and the need of land for construction of more settlements. This is also due to the reduced need of the courtyard for post-harvest activities such as threshing rice and drying grain; there is an increasing trend of carrying out these activities in mills or roadside 
commercial operations. Some sources suggest that this phenomenon of the diminishing courtyard may also be linked to a wider modernisation process, leading to reduced seclusion of women and gradual transformation of the extended family into nuclear family units (Adnan, 1996; Muktadir and Hasan, 1985). This process has the potential to bring about irrevocable transformation of the overall rural landscape, and the vanishing courtyard is simply an aspect of this larger process of change. However, it remains to be witnessed whether such a deeply rooted, widely prevalent and popular entity as the courtyard will disappear entirely or if it will persist in the future in a different form, for example its reflection in modern urban housing layouts.

It has been suggested that the elimination of courtyards may result in linear settlements, which could then facilitate the extension of infrastructural services (Muktadir and Hasan, 1985). However, although this appears to offer some advantages of physical planning, the elimination of the courtyard would also mean the loss of an intrinsic and characteristic aspect of the built environment of this region. The courtyard in the rural Bangladeshi context is not only an outdoor working space. It has special meaning for households and communities in terms of its symbolic value as an introverted, private and intimate open space at the scale of the family. It provides a sense of security particularly to women and children where they can carry out activities freely and safely within this bounded space. The climatic quality of the courtyard in terms of drawing in breeze and cooling the buildings around it is also important in this hot-humid region. It allows separating household functions such as dwelling, cooking and 
toilet, which if designed otherwise might not work as effectively in the existing rural context; it represents a time-tested indigenous site layout that has developed according to contextual requirements. For example, in planned rural settlements built by a local community development organisation, a linear grid instead of a courtyard arrangement was followed. Toilets were designed adjacent to houses and kitchens were incorporated into the dwelling units as part of a design concept for a more spatially efficient house. This was eventually found to be unsuccessful. The toilets became an irritant with bad odour wafting into the houses. The attached kitchens were converted into living spaces and new detached kitchens were later built separately away from the houses as done traditionally (Ara and Kabir, 2000).

\section{CONCLUSION}

The courtyard is a symbol of regional and vernacular architectural identity in rural Bangladesh. Although it has characteristics similar to courtyard housing in other parts of the world, such as maintaining privacy within a traditional setting and as a climatic device, the Bangladeshi courtyard is unique because of its particular type of layout with individual buildings around it defining its form. Unlike typical courtyard houses in hot-dry climates with built forms bounding the courtyard from all sides, the Bangladeshi rural homestead is composed of a number of closely spaced buildings around an open space, but clearly defining a similar introverted courtyard layout. Because of its introverted nature, it serves the need for privacy similarly as courtyard houses in other traditional Islamic societies; perhaps the form derives primarily from the requirements of 
purdah. On the other hand, the need for thermal comfort in this hot-humid climate is fulfilled by a somewhat scattered, open and porous arrangement of buildings. In order to maintain privacy and yet achieve ventilation, the gaps between the buildings potentially allowing views from the outside into the courtyard are visually obscured by the row of trees and vegetation on the outer periphery of the homestead; bamboo or grass screens are used additionally. In this way, a bounded effect as in the typical courtyard house is achieved, using a combination of built forms, vegetation and landscaping. The Bangladeshi rural courtyard is a distinctive example of form and function of space achieved by synthesising culture, climate and nature.

Although the courtyard form could be interpreted as principally a social product of patriarchal norms and hence representing the submission of women, it needs to be understood from a broader perspective. The Bangladeshi courtyard layout arises from a specific combination of social as well as environmental conditions and thus represents a regional typology - although somewhat similar to patriarchal expressions of built form elsewhere, it is unique and context-specific indicating the interplay of a wide set of factors contributing to its form. In addition to serving as a bounded space for women, the courtyard here provides a sense of belonging and identity, and weaves a collective bond between the individual dwellings and thereby family members that comprise the homestead. The courtyard is what makes the rural homestead 'home'. 
Perhaps because of technological, environmental and social changes, the courtyard in its present form might become obsolete over time. But this loss would signal the forfeiture of a longstanding cultural expression that has existed for many generations, giving rise to uncertainty on whether its replacements serve as effectively or satisfactorily. It might well be that change is inevitable and the factors that lent shape to the courtyard become no longer as relevant in line with transformations evident from current trends, such as increased access to electricity and cooling devices, revision of gender relations with women's emancipation, increased demand for land, spread of urbanisation, and mechanised agricultural production and processing. It would then be necessary to understand if and how the courtyard pattern is re-interpreted over space and time, and whether its echoes persist, and how new social, cultural and spatial meaning is imbued to a longstanding regional archetypal spatial pattern.

\section{REFERENCES}

Adnan, S (1996) "A Harsh Freedom: Contradictory Aspects of Change in Women's Position in Bangladesh". Paper presented at the South Asian Studies Programme. Oxford, University of Oxford.

Ahmed, I (1997) "Kitchen", "Bangladesh", "Bengalee" and "Namoshudra" in

Oliver, P (ed) Encyclopedia of Vernacular Architecture of the World. Cambridge, Cambridge University Press.

Ahmed, I (2003) "Rural Architecture" in Islam, S. and Miah, S. (eds) National Encyclopedia of Bangladesh. Dhaka, Asiatic Society. 
Ahmed, I and Kabir, H (2005) A Study of Traditional Housing of the "Pahari" Communities in the Chittagong Hill Tracts (research report). Dhaka, Bangladesh University of Engineering \& Technology.

Ara, Y and Kabir, R (2000) "Rural Housing Initiative by Development Agencies in Bangladesh: Miles to Go" in Hodgson, R, Seraj, S and Ahmed, I (eds) Village Infrastructure to Cope with the Environment. Dhaka, Bangladesh University of Engineering \& Technology and Exeter, UK, University of Exeter.

Chowdhury, TA (1992) Segregation of Women in Islamic Societies of South Asia and its Reflection in Rural Housing - Case Study in Bangladesh (MArch thesis). Montreal, McGill University.

Hasan, DM (1985) A Study of Traditional House Forms in Rural Bangladesh (MArch thesis). Dhaka, Bangladesh University of Engineering and Technology.

Hasan, DM (1987) A Study of Building Process of Houses in Rural Bangladesh: The Case of Floodplain Region (Master of Engineering in Architecture thesis). Leuven, Belgium, Katholieke University.

Islam, N et al (1981) "A Survey of Housing in a Bangladesh Village". Paper presented at the Regional Workshop on Transfer of Rural Housing Technology. Dhaka, Centre for Urban Studies.

King, AD (1984) The Bungalow: The Production of a Global Culture. Boston, Routledge and Kegan Paul. 
Muktadir, MA and HASAN, DM (1985) "Traditional House Form in Rural Bangladesh" in Powell, R and KHAN, IM (eds) Regionalism in Architecture. Singapore, Concept Media.

Olgay, V (1963) Design with Climate. New Jersey, Princeton University Press. Rahman, MM (1996) "Evolving Environmental Ideals of Old Dhaka: A Study into Tenement Houses". Paper presented at the 14th Conference of the International Association of People-Environment Studies (IAPS). Stockholm.

Sultana, S (1993) Rural Settlements in Bangladesh: Spatial Pattern and Development. Dhaka, Graphosman. 